\title{
An epidemiologic study of animal bites in North Khorasan Province, Iran, from 2005 to 2011
}

\author{
Alavinia SM, MD-PhD ${ }^{1}$, Yaghubi M, BSc ${ }^{2}$, Rajabzadeh R, MSc ${ }^{3}$, Seyed Sharifi SH, MD ${ }^{4 *}$ \\ 1- PhD of Clinical Epidemiology, Vector-Borne Diseases Research Center, North Khorasan University of Medical Sciences, \\ Bojnurd, Iran. 2- BSc in Nursing, Intensive Cardiac Care Unit, 9Day Hospital, Torbat Heydariyeh University of Medical \\ Sciences, Torbat Heydariyeh, Iran. 3- MSc Student of Epidemiology, Vector-Borne Diseases Research Center, North Khorasan \\ University of Medical Sciences, Bojnurd, Iran. 4- MD Student, Research Committee, School of Medicine, North Khorasan \\ University of Medical Sciences, Bojnurd, Iran.
}

Abstract

Received: May 2015, Accepted: June 2015

Background: Animal bite is an important and preventable health hazard. This study aimed to determine the epidemiology of animal bites in North Khorasan Province in Iran.

Materials and Methods: Data gathered from health centers from March 2005 until December 2011 were used for this cross-sectional descriptive study of animal bites.

Results: A total of 18,517 animal bite cases were reported during the study period. The victims were predominantly male (66\%). The most affected persons were residents in rural areas (80.7\%). Most victims had been bitten by dogs (90.5\%). The number of patients with incomplete vaccinations was 16,232 (88.1\%) compared to 2,185 (11.9\%) completely vaccinated patients. The highest rate of animal bite cases was reported from Bojnurd County, Iran. The incidence of animal bites in North Khorasan increased from 255.05 per 100,000 in 2005 to 365.18 per 100,000 in 2011.

Conclusions: Since the incidence of animal bites has increased in recent years, the dog population should be controlled and domesticated animals should be vaccinated. Education about animal bite prevention is an important strategy for preventing this problem and, consequently, rabies.

Keywords: Bites, Epidemiology, Incidence, Vaccination, Rabies.

\section{Introduction}

Rabies is an acute, progressive, and fatal zoonotic disease. Human rabies is associated with the rise of civilization, the growth of cities, and domestication of animals, especially dogs (1). Rabies is a major public health concern in some countries including Iran. The highest incidence of human rabies cases in Iran was reported during 1995-1999 in Chaharmahal and Bakhtiari and Fars Provinces (2). The collection and analysis of data about animal bites, can help to control and prevent this disease.

Animal bite is defined as a bite or claw wound from a pet, or farm or wild animal (3). Animal bites were reported throughout the year with the highest bite incidence occurring during the spring. In different human groups, children (aged 5-9 years) are the most frequent victims of animal bites, and men are 1.15 times more likely to report dog bites compared to women (4). A survey conducted during 2001-2003 in the USA estimated 4.5 million dog bites each year (an incidence rate of 1,660/100,000 in adults and $1,310 / 100,000$ in children) (5). The annual incidence of animal bite in Iran is estimated as 140 cases per 100,000 population (6), and has been increasing in recent years (7). Almost 94\% of animal bite cases are inflicted by domestic

\footnotetext{
* Corresponding author: Seyed Hassan Seyed Sharifi, MD Student, Research Committee, Medical School. North Khorasan University of Medical Sciences, Bojnurd, Iran. Email: Hsharifi368@yahoo.com
} 
animals such as dogs and cats, and wild and stray animals, such as wolves, jackals, and foxes, constitute $16 \%$ of cases (8).

Moreover, death rate due to dog bites in Australia, United States, and Canada are 0.004, $0.05-0.07$, and 0.007 per 100,000 , respectively (9).

Rabies is a fatal disease that is considered a reemerging zoonosis throughout much of the world. Rabies satisfies all the World Health Organization (WHO) criteria for diseases that are a priority for control. In addition, safe and effective animal and human vaccines are widely available for its prevention and control. Preexposure treatment (PET) in animals and humans is an effective way of decreasing the costs of rabies. PET for humans is an effective, but costly way to prevent clinical problems with rabies, but does not provide a permanent solution to rabies in the future. The cost of PET in Asia was US \$ 49.41 per patient and in Africa was US \$ 39.5721 per patient, in 2011 (10).

Epidemiological studies have confirmed that the majority of injured patients resided in rural areas. The first step in preventing diseases related to animal bites, such as rabies, is to identify the associated risk factor.

The aims of this study were to determine the incidence of animal bites as well as the characteristics of the bitten persons and biting animals, and wound in North Khorasan Province of Iran.

\section{Materials and Methods}

In this cross-sectional descriptive study, data were obtained from patients who suffered from animal bites and referred to health centers located in North Khorasan Province from March 2005 to December 2011.

By law, all bite victims should be referred to health centers for treatment, and all animal bite cases are emergency cases. Thus, data (characteristics of the bitten persons and biting animals, and month of biting) were obtained from the data bank of all health centers in the city and rural areas covered by the North Khorasan Universities of Medical Sciences, Iran. The obtained data were recorded in a checklist. The results were entered into Microsoft Excel 2010 with pull down notes and analyzed using SPSS statistical software package (version 18, SPSS Inc., Chicago, IL, USA).

\section{Results}

During the study period (2005-2011), 18, 517 (66\% males and 34\% females) individuals had been treated for animal bites (Figure 1). The incidence of animal bite in North Khorasan Province was estimated as $255,258,302,321$, 330,359 , and 365 per 100,000 in 2005,2006 , 2007, 2008, 2009, 2010, and 2011, respectively. The animals were dogs in $16,670(90.5 \%)$, goats in $799(4.34 \%)$, cats in $697(3.78 \%)$, wild goats in $146(0.8 \%)$, wolves in $48(0.26 \%)$, jackals in $29(0.16 \%)$, and foxes in $28(0.15 \%)$ cases (Figure 2). The animals were domestic in $84.8 \%$ of cases, wild in $1.4 \%$, and stray animals in $13.8 \%$ of cases. Of the injured patients, 14,950 $(80.7 \%)$ were living in rural and 3,567 (19.3\%) in urban areas.

The highest rate of human bite cases were reported in Bojnurd, Iran (Figure 3). The number of individuals who were bitten by animals during the study period in different districts of North Khorasan Province is presented in Figure 3 . Up to 16,232 patients were treated by noncompleted vaccination (88.1\%), and 2,185 $(11.9 \%)$ with completed vaccination. The peak incidence of animal bite cases was reported in June. The monthly distribution of animal bite cases (average animal bites per month per year) is shown in figure 4. The incidence of animal bite increased during the study period from 255 per 100,000 in 2005 to 365 per 100,000 in 2011. 


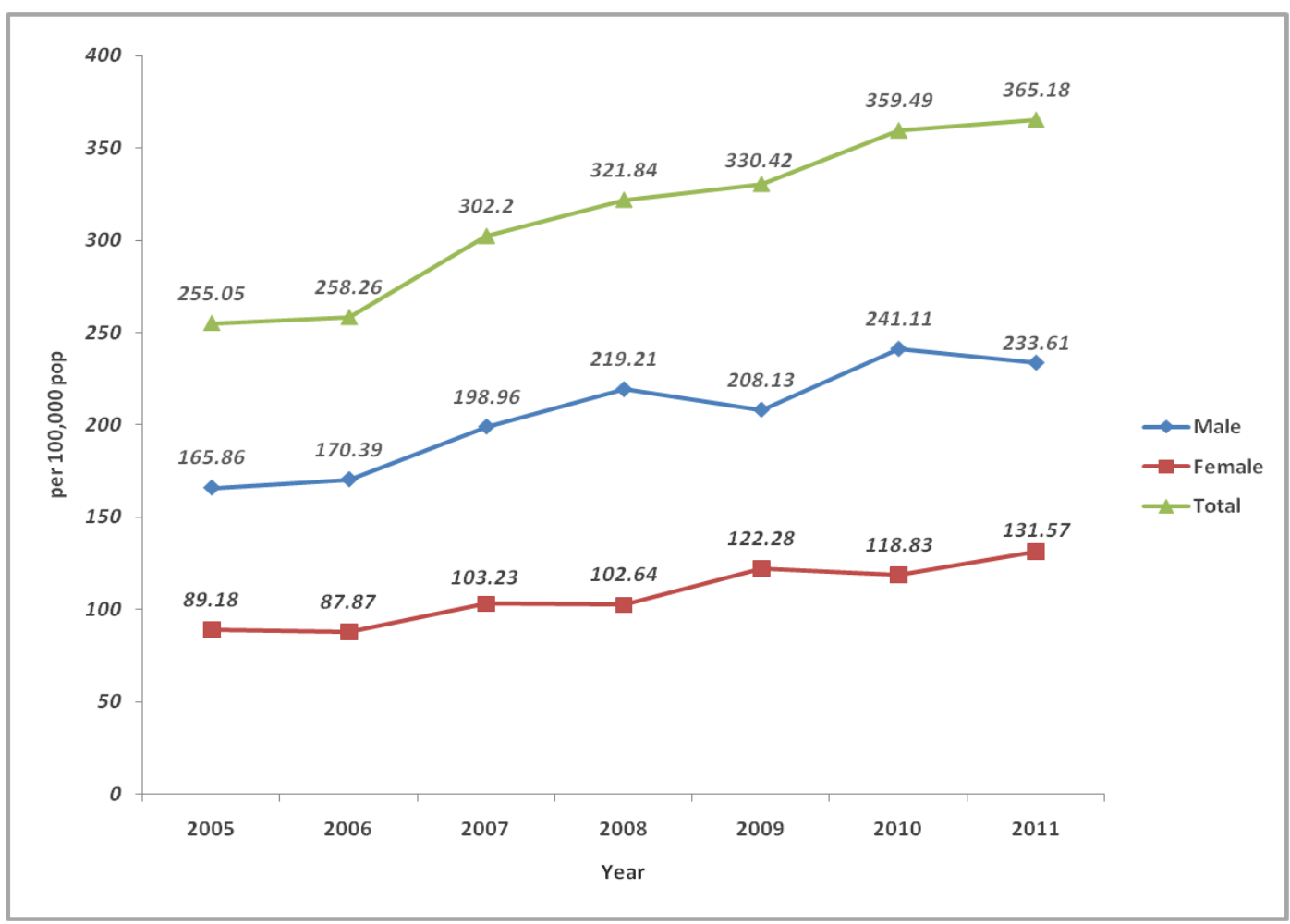

Figure 1: Distribution of the rate of animal bites detected in North Khorasan Province, Iran, from March 2005 to December 2011 according to sex and total rate per 100,000 population

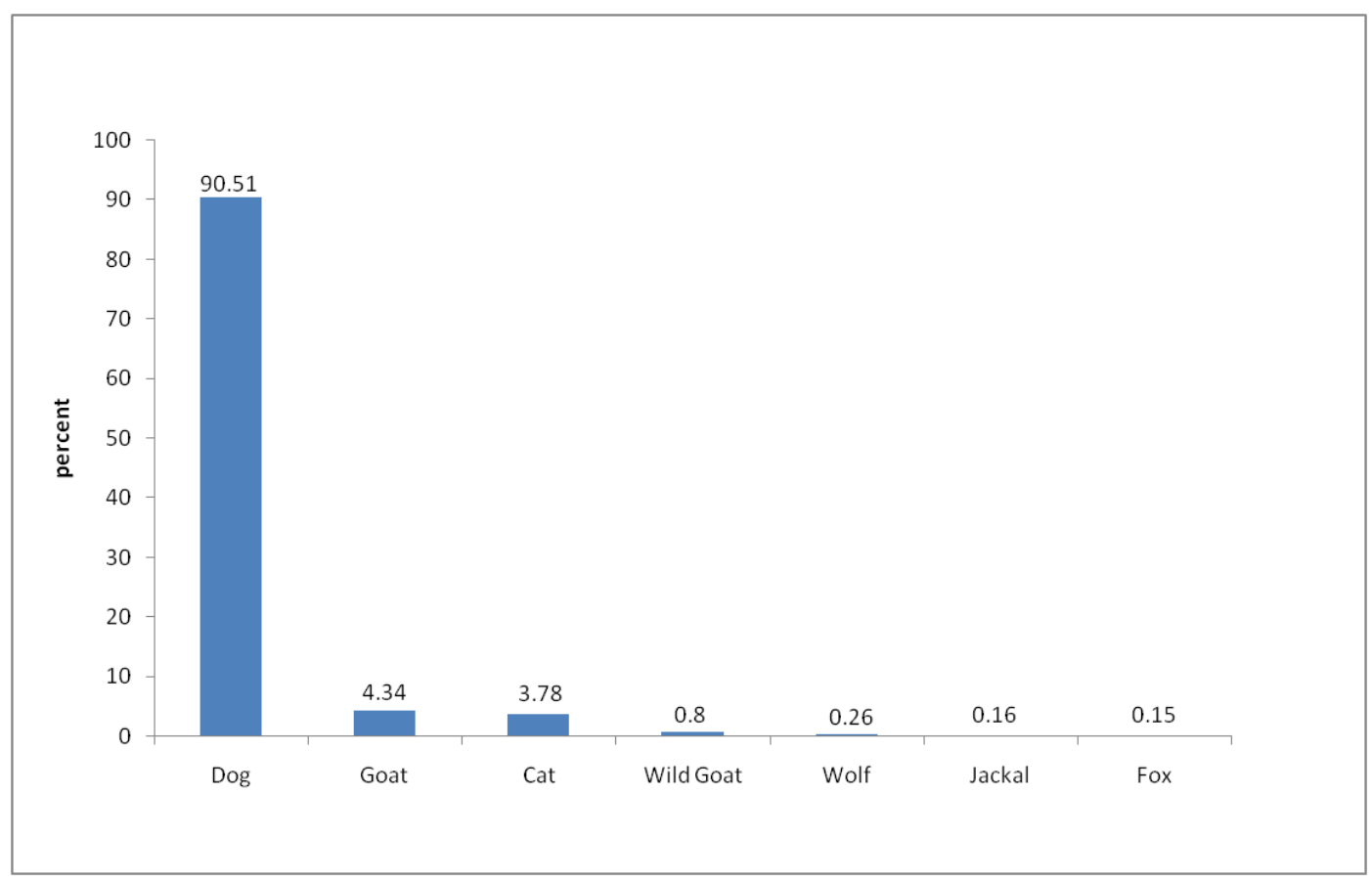

Figure 2: Distribution of animal bites detected in North Khorasan Province, Iran, from March 2005 to December 2011 according to animal species 


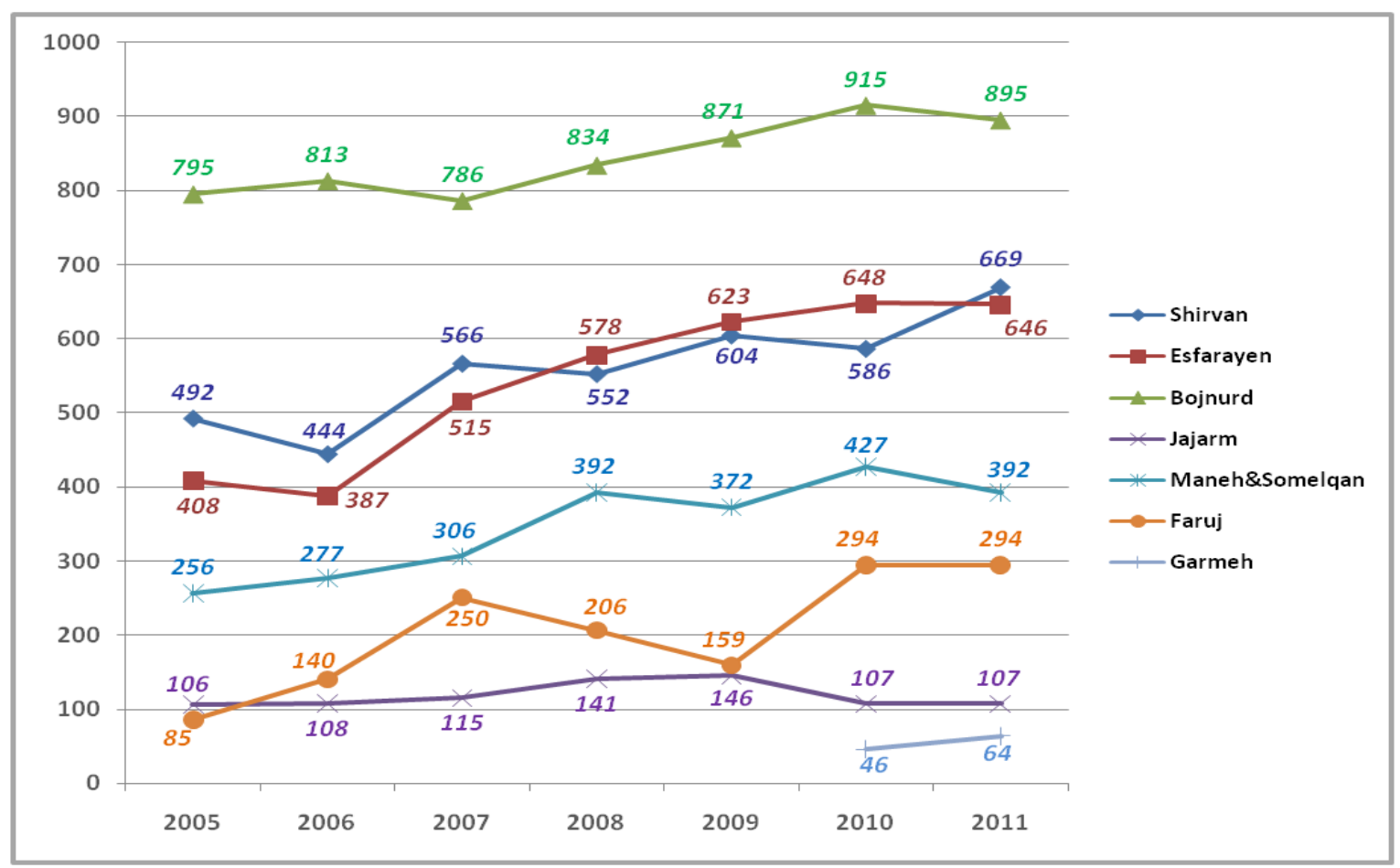

Figure 3: Distribution of animal bites detected in North Khorasan Province, Iran, from March 2005 to December 2011 according to different districts of North Khorasan Province

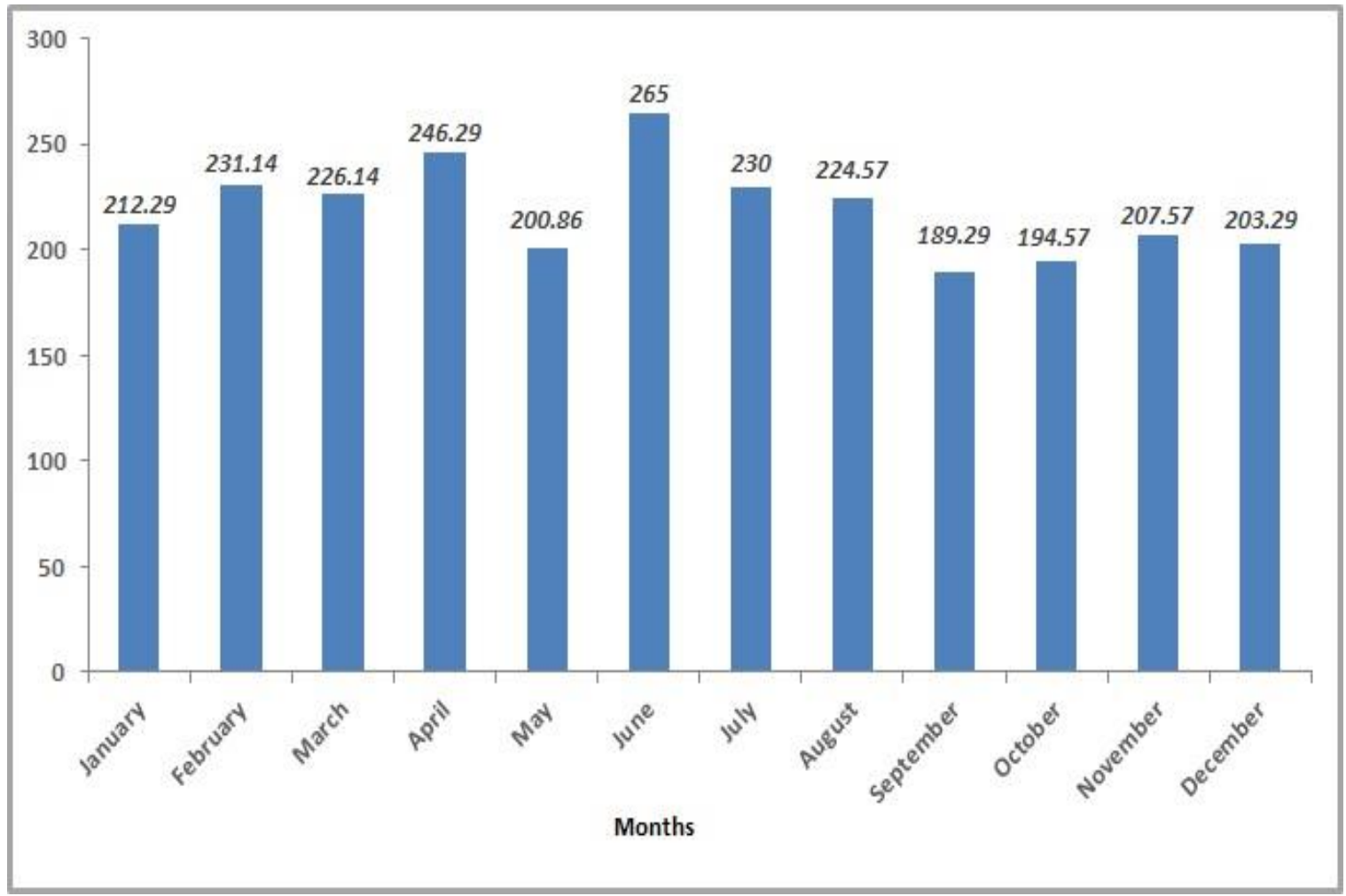

Figure 4: Distribution of animal bites detected in North Khorasan Province, Iran, from March 2005 to December 2011 according to average monthly number of animal bite cases per year 


\section{Discussion}

The incidence of animal bite in North Khorasan Province increased during the study period from 255 per 100,000 in 2005 to 365 per 100,000 in 2011. The incidence of animal bite in different parts of Iran has also increased from 35.1 per 100,000 in 1987 to 151 per 100,000 in 2001 (11).

A study in Ilam Province also showed that the incidence of animal bites in Ilam increased from 34 per 100,000 in 1999 to 98 per 100,000 in 2008 (8). Another report from Rafsanjan, Southeast of Iran, has indicated that the rate of animal bites increased from 180 per 100,000 in 2003 to 214 per 100,000 in 2004 (12). The causes of this rise are not known. It might be the result of increased number of health centers and more coverage of population, and therefore, access to public health services for a greater number of patients. It may also be related to the number of stray dogs $(4,13)$.

Of all the animal bite cases reported during a 7year period, $80.7 \%$ were living in rural and $19.3 \%$ in urban areas. This observation was similar to that of a study performed in Birjand, Iran, in which $64.2 \%$ were living in rural areas and $35.8 \%$ were urban residents (14). In a study performed in India it has been shown that the incidence of animal bites in rural areas is higher than urban areas (15).

Among the study population, 12,071 (66\%) were male and 6,346 (34\%) were female, which is similar to previous studies on this topic. In a study performed between 1998 and 2008 in Ilam, 3,032 (68.3\%) of those who were bitten by animals were male and $1,398(31.7 \%)$ were female (8). In the surveys performed in Tehran and Kerman Provinces, and cities of Birjand and Rafsanjan, the majority of bitten individuals were male $(3,12,14,16)$. In a study in Bali, there were 104 human rabies cases from 2008 to 2010, most were male $(56.7 \%)$ and from rural districts, and almost all (92\%) cases had a history of dog bite (17). It seems that the main cause of higher rates of bites in men than women is that men are more exposed to animals in their daily life, especially in rural areas. However, in a survey performed in USA, most animal bite cases were female (18). This issue may be resulted from the different cultural behaviors in that country. In Iran, people do not keep animals in their houses, but this is common in other countries such as USA.

In the present study, dog bite was the most common cause of injuries in victims. A survey performed in Rafsanjan showed that the most frequent bites were from dogs $(74 \%)$, cats (23\%), and other animals (3\%) (monkeys, rats, foxes, donkeys, and etc.) (12). In another study performed in Ilam Province, it has been shown that dog bites were more common [3,942 $(89.2 \%)$ ], followed by cats $(5 \%)$, wolves $(0.7 \%)$, jackals $(0.6 \%)$, foxes $(0.3 \%)$, and other animals (4.2\%) (8). In the present study, most patients were bitten by domestic animals. Similarly, the result of a study in Rafsanjan, Southeast of Iran, showed that the victims were bitten by domestic animals in $77.8 \%$ of cases, stray in $20 \%$, and wild animals in $3 \%$ of cases (12). In another study performed in Japan, most victims were injured by stray or domestic dogs (19).

In the current study, the number of patients incompletely and completely vaccinated was $16,232(88.1 \%)$ and 2,185 (11.9\%), respectively (14). In comparison, in a survey performed in Birjand, $81.9 \%$ of cases had received incomplete vaccination while $18.1 \%$ had received complete vaccination. In a survey in Kerman, Iran, on patients bitten from 1994 to 2003, incomplete and complete rabies vaccination was performed in $79.36 \%$ and $20.64 \%$ of cases, respectively (16). The high level of incomplete vaccination in victims might be due to treatment protocol of animal bites.

This study had some limitations, such as the lack of organized data between 2011-2015. Hence, we decided to report all organized data in this paper. Another limitation in this article was the 
lack of records about the site of the animal bite in the study population. Therefore, it is suggested that this issue be considered in future studies.

\section{Conclusion}

According to the results of this survey, $84.8 \%$ of all victims were bitten by domestic animals; therefore the vaccination of domestic animals should be considered as an important policy in health care system.

In conclusion, the findings of this study showed that animal bites remain a very important problem in North Khorasan Province. Hence, in order to decrease the rate of this health problem and consequently rabies and other related diseases, the eradication of stray dogs, vaccination of domestic animals, and educational programs should be organized by health authorities.

\section{Acknowledgement}

The authors are grateful to staff of the health center of North Khorasan University of Medical Sciences for their assistance with data collection.

\section{Conflict of interest: None declared}

\section{References}

1. Rupprecht CE, Hanlon CA, Hemachudha T. Rabies re-examined. Lacent Infect Dis 2002; 2(6):327-43.

2. Simani, S. Epidemiologic survey of human rabies in Iran from 1995 to 2000 . J Infect Dis Trop Regions 2002; 16:42-8.

3. Eslamifar A, Ramezani A, Razzaghi-Abyaneh M, Fallahian V, Mashayekhi P, Hazrati M, et al. Animal Bites in Tehran, Iran. Arch Iran Med 2008; 11(2):200-2.

4. Tenzin, Dhand NK, Gyeltshen T, Firestone S, Zangmo C, Dema C, et al. Dog bites in humans and estimating human rabies mortality in rabies endemic areas of Bhutan. PLoS Negl Trop Dis 2011; 5(11):e1391.

5. Gilchrist J, Sacks JJ, White D, Kresnow M. Dog bites: still a problem? Inj Prev 2008; 14(5):296301.

6. Alavi SM, Alavi L. Epidemiology of animal bites and stings in Khuzestan, Iran, 1997-2006. J Infect Public Health 2008; 1(1):51-5.

7. Brook I. Microbiology and management of human and animal bite wound infections. Prim Care 2003; 30(1):25-39.

8. Sabouri Ghannad M, Roshanaei G, Rostampour F, fallahi A. An epidemiologic study of animal bites in Ilam Province, Iran. Arch Iran Med 2012; 15(6):356-60.

9. Abuabara A. A review of facial injuries due to dog bites. Med Oral Patol Oral Cir Bucal 2006; 11(4):E348-50.

10. Wera E, Velthuis AG, Geong M, Hogeveen H. Costs of rabies control: an economic calculation method applied to Flores Island. PLoS One 2013; 8(12):e83654.

11. Akbari M. The epidemiologic study of animal bites in Iran. Tehran: Ministry of Health and Ministry of Medical Education; 2005:50

12. Sheikholeslami NZ, Rezaeian M, Salem Z. Epidemiology of animal bites in Rafsanjan, southeast of Islamic Republic of Iran, 2003-05. East Mediterr Health J 2009; 15(2):455-7.

13. Bhutan Observer. Who lets the dog out? [Internet]. 2008 [updated 2008 Apr; cited 2010 Nov 20]. Available from:http://www.bhutanobserver.bt/ 2008/bhutan-news/04/ who- let- the- dog- out. html.

14. Bijari B, Sharifzade GR, Abbasi A, Salehi S. Epidemiological survey of animal bites in east of Iran. . Iranian journal of clinical infectious diseases 2011; 6(2):90-2.

15. Sudarshan MK, Mahendra BJ, Madhusuana SN, Ashwath Narayana DH, Rahman A, Rao NS et al. An epidemiological study of animal bite in India: results of a WHO sponsored national multicenteric rabies survey. J Commun Dis 2006; 38(1):32-9.

16. Rezaeinasab M, Rad I, Bahonar AR, Rashidi H, Fayaz A, Simani S, et al. The prevalence of rabies and animal bites during 1994 to 2003 in Kerman province, southeast of Iran. Iranian Journal of Veterinary Research, University of Shiraz 2007; 8(4):343-50.

17. Susilawathi NM, Darwinata AE, Dwija IB, Budayanti NS, Wirasandhi GA, Subrata K et al. Epidemiological and clinical features of human rabies cases in Bali 2008-2010. BMC Infect Dis 2012; 12:81.

18. Freeman AJ, Senn DR, Arendt DM. Seven hundred seventy eight bite marks: analysis by anatomic location, victim and biter demographics, type of crime, and legal disposition. J Forensic Sci 2005; 50(6):1436-43.

19. Takayama N. Study on the subjects received postexposure rabies vaccination in our vaccine clinic. Kansenshogaku Zasshi 1995; 69(1):73-8. 